\title{
The Importance of Understanding Culture When Improving Education: Learning from Cambodia
}

\author{
Jan B. Y. Berkvens ${ }^{1}$ \\ ${ }^{1}$ Consultant to UNESCO Afghanistan \\ Correspondence: Jan B. Y. Berkvens, Consultant at UNESCO Afghanistan. E-mail: janberkvens@gmail.com
}

Received: February 24, 2017

Accepted: April 17, $2017 \quad$ Online Published: August 27, 2017

doi:10.5539/ies.v10n9p161

URL: https://doi.org/10.5539/ies.v10n9p161

\begin{abstract}
Following Education for All, initiatives like child-friendly schools initiative, are rolled out in many countries, including Cambodia. The child-friendly schools initiative is addressing general and local needs of children in schools, like a safe environment, well-trained teachers and the provision of teaching and materials. But there is also a component that is more cultural in nature and might not resonate well with the country's culture. As Hofstede's $(1980,1986)$ research concerning cultural differences indicated, a country's culture can be described following five dimensions (individualism/collectivism, power distance, uncertainty avoidance, masculinity/femininity, and long-term/short-term orientation). Not taking a country's culture into account while intervening with important services like education, might lead to low intervention outcomes, teachers who feel uncomfortable with the proposed contents and ways of teaching, and students who are not prepared well towards the society they live in. A cultural profile of Cambodia was missing when the ministry of education started to roll out the Education for All and Child Friendly School approaches in 2006/2007 (Schaeffer \& Heng, 2016). The original research has since been enriched with additional data sets. The data sets are by no means large enough to be representative, but through triangulation a careful attempt is made to at least inform educationalists of the importance of taking culture into account when designing and implementing educational interventions to improve learning in Cambodia, and likely elsewhere. With the onset of the Sustainable Development Goals (UN Sustainable Development Knowledge Platform, 2015), such cultural understanding is a necessity in order to achieve cultural appropriate project outcomes.
\end{abstract}

Keywords: educational development, Cambodian culture, Southeast Asian culture, Cambodia, child friendly schools

\section{Introduction}

\subsection{The Need for a Cultural Profile}

Since Cambodia committed itself to the millennium development goals, to provide education to all children by the end of 2015, the Cambodian Ministry of Education, Youth and Sports (MoEYS) and international partners have invested enormous amounts of money and staff capacity in achieving Education for All (EfA) and Child Friendly School (CFS) programs. Schools are constructed, new teachers trained, and materials developed. Capacity development was foreseen for almost every person in the educational system. Education interventions like CFS had and still have a positive impact on education delivery and children's learning. Teaching and learning materials have been distributed in large amounts and school environments have become safer and more inviting to learn. But other, more culturally sensitive sides of these initiatives call for cultural understanding. A comprehensive representation of Cambodian culture beyond experiential and anecdotal evidence was missing at the time of research. This research tries to unpack Cambodian culture following the five cultural dimensions of Hofstede $(1980,1986)$, and shows how some notions of CFS do not fit the Cambodian cultural context without adaptations. The outcomes could help to further contextualize educational interventions in Cambodia with the 2030 development agenda in mind.

Aside from the more general important components of CFS initiatives, like school construction and materials distribution, CFS tries to influence educational culture, which is heavily intertwined with the national culture. Stecher states that 'schools are both recipients and creators of cultural patterns, and over the long term they help to shape norms for the next generation' p.20 (The Economist Intelligence Unit, 2012). This statement implies that a nation that wishes to foster new competences should start with introducing these in national education, 
while at the same time the educational system is a powerful conservator of culture itself. Teachers that are often seen as important change agents are themselves raised in the national system of cultural beliefs. Therefore, it is important to understand the national culture and its influence on education. Such a cultural profile did not exist at the time of research, and sources that where available were experiential and anecdotal. What is available is in the form of non-substantiated cultural guides like 'Cambodian do's and don'ts' (Hill, 2005) and more anecdotal evidence in the form of handouts, paragraphs in guidebooks and oral advice (VSO, 2006). This research tries to fill the gap, while acknowledging that it is in no way representative for the whole nation as a result of the limited size of the research.

The original research into a cultural profile for Cambodia was part of a dissertation into developing professional learning in Cambodia (Berkvens, 2009). The more extensive $\mathrm{PhD}$ research supported a contextualized professional development approach for Ministry of Education staff, responsible for the roll out of EfA and CFS programs around the country. As the roll out of these programs demanded extensive training throughout the education sector, a culturally relevant training approach was sought. Because the research into a cultural profile for Cambodia at the time was limited and only a sideline in the dissertation, additional research has been done in 2012 and recently in 2016. The research question for the research presented in this article is as follows:

How would a cultural profile of Cambodia look like, in order to support educational interventions like child-friendly schools and the 2030 development agenda, in a way that respects Cambodian national culture?

In order to understand why the cultural profile for Cambodia presented as a result of this research is more complex than that of many other countries, it is necessary to unveil Cambodia's history before going into the methodology and outcomes of the research. More elaborate sources on Cambodia's history will do the country's past much more credit than the brief description given here (see for example Chandler, 2007).

\subsection{Cambodia's Past and Present}

Contemporary Cambodian culture is complex. It would be too simple to approach Cambodian culture as being 'Southeast Asian' only, as the influence of the conflicts that were experienced by Cambodian society over the last 40 years are just too immense. The legacy of war and occupation and the succession of regimes, each of them with their own ideology, was-and remains-tremendous. Having been pulled into international conflicts in the past, being occupied by Vietnam and Russia followed by the return to sovereignty, many ideologies that have never been their own, current Cambodian culture is strongly affected by these historical influences. Western and regional support brings yet other influences that are, more often than not, contradicting Cambodian culture.

\subsubsection{History until the Khmer Rouge Period}

Cambodian history until the 1970's consists roughly of the pre-Angkorian period, the Angkor period, followed by a long period of peasantry, the French protectorate and the sovereign monarchy of King Sihanouk. During the pre-Angkorian and Angkorian period, Indian migrants influenced large parts of Southeast Asia, including what is now known as Cambodia. Their influence on the Khmer social system is characterized by the importance of reciprocal relationships and dependencies, leading to a complex social hierarchy. Kings were persons of almost mythical proportions, protecting society. The temples of Angkor symbolize the traditional Cambodian concepts of power, embodying absolutism and hierarchy (Ayres, 2000).

When the French forced a protectorate upon Cambodia in 1863, their mission aimed to assimilate the Khmer (ethnic Cambodians) into a French-style system of governance. Although executed half-heartedly, the French felt an obligation to improve the social, cultural and material status of the Khmer. They did so with a complete lack of understanding of Cambodia and its people. At the end of their rule in 1953, the French had been unable to spread their egalitarian philosophy. They did, however, help to reinforce the power of the Cambodian monarchy and raised the profile of King Sihanouk.

The era of King Sihanouk's rule over Cambodia, from the 1950's to the 1960's still has a kind of mythical connotation for many Cambodians. Sihanouk was a ruler with totalitarian features, who also claimed that people should be allowed to enjoy the benefits of their efforts. This ideology enabled Sihanouk to retain total control while promoting economic development and following Buddhist teachings. Ayres (2000) negates this general belief by describing it as a regime characterized by political repression, state-sanctioned violence, factionalism, corruption, incompetence, and absolute contempt by the powerful towards those ruled by them. Fröberg Idling (2009) has a more positive interpretation, showing that although the regime was corrupt, it also worked towards prosperity for the country.

Khmer intellectuals, who were well educated and had become intrigued by communist values during their 
studies in France, returned to Cambodia in the time of awakening nationalism and called for more influence for the people. They started to question the nature of the Khmer social system. They promised the Cambodians what was denied to them by the Royal Government: equality and more widespread prosperity. Ayres (2000) claims that it is unlikely that many were true communists: what drove them was merely dissatisfaction with the 'decadence and corruption in Phnom Penh' (p. 61).

Some of the communist intellectuals, like Ieng Sary and Pol Pot, turned their conviction into radical actions. Where the French did not understand Khmer culture very well and thus were virtually unable to break traditional power relations and hierarchical systems, the French-educated leaders of the Khmer Rouge were able to do exactly that.

\subsubsection{The Khmer Rouge Era}

In the beginning, many Cambodians were relieved when the Khmer Rouge entered the capital on April 17, 1975. The Khmer Rouge was thought to bring hope after a long period of uncertainty in which both national and international political relations had been confusing. However, the next day the people of Phnom Penh and other towns were forced to leave their cities on foot and go to the paddy fields in the countryside, a journey from which many did not return.

The driving force behind the Khmer Rouge was the former Khmer French student Saloth Sar, later known as Pol Pot. Ironically, the leaders of the Khmer Rouge, being intellectuals themselves, ordered the dismantlement of city life and destruction of the Cambodian intellectual community. They were communists and strove for egalitarianism: Buddhism, ownership of property and the monarchy were terminated. Money was declared worthless and family ties were cut. Individualism, seen as a modern thing from the West, was abandoned in favor of collectivism and anonymity.

Compared to the previous administrations, the Khmer Rouge regime shows some similar and some very different features. Almost all Khmer regimes since independence embraced the power of their ancient predecessors as their own: Khmer superiority and power were seen as unsurpassable. The three regimes, of King Sihanouk, the intermediate Lon Nol regime and the Khmer Rouge were conducted with the conviction that they were completely legitimate in that sense. Opposition and criticism were eliminated by force. The Khmer Rouge despised the corruption, decadence, nepotism, exploitation of the poor, and unbridled capitalism of the elite that had thrived under the former regimes. But the Khmer Rouge inversed the Khmer class system.

The Khmer Rouge regime was horrific. Many died during the marches to the working fields, or from the unbearable harshness of life in the paddies with their long working hours, scarcity of food and lack of medical care. Possible opponents of the regime and intellectuals were tortured and killed. At the end of the Khmer Rouge rule not only had most of the Cambodian intellectuals been killed, but also the more educated cadres (Ayres, 2000). This contributes to quite a different situation compared to that of other post-conflict countries like Germany and Rwanda, where at least a reservoir of intellectuals remained to draw from when the rebuilding process was initiated. Secondly, in contrast with the Nazi regime, during which the Germans suppressed Jews, Gypsies and homosexuals, and the Rwandan Tutsi-Hutu conflict, the Khmer Rouge were Cambodians fighting Cambodians. This had and still has complicated consequences for the reconciliation process in Cambodia.

Vietnamese forces defeated the Khmer Rouge regime, on January 7, 1979. The regime left almost two million Cambodians dead out of a population of almost eight million. Of those families who were reunited, people either returned to their hometowns or, as many did, fled to neighboring countries.

\subsubsection{From Vietnamese Occupation to Sovereignty}

After the defeat of the Khmer Rouge, Cambodia was found completely destroyed. The Khmer Rouge had eliminated the education system, civil services, the health sector, and had ruined Cambodia's agricultural sector. It also became clear that the country was depleted of its educated inhabitants. The Vietnamese installed a socialist Government, consisting of many defected Khmer Rouge cadres. Education was used as a channel for spreading-and sometimes indoctrinating-young people with the new socialist state ideology.

The Vietnamese occupation of Cambodia ended mid-1989. After the United Nations-led Paris Peace Treaty was signed on October 23 1991, the formerly fighting factions declared a cease-fire, although fighting continued in some parts of the country until the late 1990's (Peterse \& Petri, 2004; Taylor, Wheeler, \& Robinson, 1996; Verkoren, 2005). Cambodia's isolation had ended. A constitution characterized by pluralism (recognition of a broad range of convictions) was installed and the first elections were held in 1993. The elections resulted in a 'two-state' Government: two Prime Ministers started to lead the country, with two supporting parallel power structures making and executing policy (Ayres, 2000; Verkoren, 2005). Despite the pluralistic constitution, both 
Prime Ministers tried to extend their legitimacy with the same notions of power and leadership, reinforcing hierarchy, ranking, hegemony and servitude, as their predecessors before the Khmer Rouge era.

Currently, Cambodia is changing fast. The economic growth figure of a steady $9 \%$ over the last 10 years (ADB, 2008) has its impact on society. Cambodia seems to have caught up with the worldwide globalization processes that influence all of us.

\subsubsection{Hofstede's Five Dimensions of Cultural Differences}

In order to answer the research question (how a cultural profile for Cambodia would look like), Hofstede's five dimensions of cultural differences (Hofstede, 1986; Hofstede \& McCrae, 2004) was used as a framework to investigate and describe Cambodian culture. Hofstede's work is still one of the leading models for describing culture. The model, depicted in table 1, is constructed of five dimensions that could each be understood as continuums. By positioning a culture along each continuum, a cultural profile arises, which can then be compared with the cultural profiles of other nations.

The first dimension is the individualism-collectivism dimension. This dimension describes what the most common unit is for which members of a society take responsibility. The second dimension positions the power distance of a society: it reflects to what extent less powerful people accept inequality in power as being normal. The next dimension, of uncertainty avoidance, gives a measure for the extent to which people become nervous by situations that they perceive as unstructured, unclear and unpredictable. The fourth dimension positions a society on the masculinity/femininity continuum. It is important to understand the definition on which this dimension is based. It describes the extent to which masculine or feminine traits dominate behavior in society. In both extremes, males usually remaining dominant in political and work settings, but it is their behavior that is either more masculine or feminine. The fifth dimension was added in later versions of the model and describes the long-term or short-term orientation of a society.

Table 1. Hofstede's 5-D model for cultural differences

\begin{tabular}{lll}
\hline Dimension & Description \\
\hline \multirow{3}{*}{ Individualism/Collectivism } & $\begin{array}{l}\text { This dimension describes the units for which members of a society take responsibility. Cultures } \\
\text { that are individualist see personal interest and interest for immediate family as the unit of } \\
\text { responsibility, whereas collectivist societies embrace larger groups of people that are related or } \\
\text { interrelated, in their 'in-groups'. Individualist societies are loosely integrated, collectivist ones } \\
\text { tightly. }\end{array}$ \\
\hline \multirow{3}{*}{ Power distance } & $\begin{array}{l}\text { Power distance reflects the extent to which less powerful people accept inequality in power as } \\
\text { being normal. The smaller the power distance, the less people accept these differences in power. } \\
\text { The larger the power distance, the more people accept these differences. }\end{array}$ \\
\hline Uncertainty avoidance & $\begin{array}{l}\text { Uncertainty avoidance is the extent to which people are made nervous by situations that they } \\
\text { perceive as unstructured, unclear or unpredictable, and to what extent they maintain strict codes of } \\
\text { behavior and beliefs in absolute truths to counteract uncertainty. }\end{array}$ \\
\hline Masculinity/Femininity & $\begin{array}{l}\text { The masculinity-femininity dimension is based on the social roles of men and women, associated } \\
\text { with biological facts between the two sexes. However, for both types of society, males remain } \\
\text { dominant in political and work organizations. Feminine societies tend to demonstrate more } \\
\text { overlapping social roles for men and women, for example being less ambitious or competitive, } \\
\text { and paying more respect to anything that is small, weak and slow. Students in more masculine } \\
\text { societies tend to overrate their self-performance, which is the opposite in more feminine societies. }\end{array}$ \\
\hline Song-term/Short-term orientation & $\begin{array}{l}\text { Societies with a long-term orientation are more frugal and persevering, whereas countries with a } \\
\text { short-term orientation try to respect tradition, have a stronger social commitment and prevent } \\
\text { people from losing face. }\end{array}$ \\
\hline
\end{tabular}

\section{Methodology}

\subsection{Introduction}

A mixed method was used to arrive at the cultural profile of Cambodia presented here. It is important to keep in mind that the original aim of the cultural endeavor was not to execute a full-blown research with fully randomized and representative samples, but only to come to a somewhat more substantiated description of Cambodian culture to support the more extensive thesis on more successful capacity development in the education sector in Cambodia (Berkvens, 2009; Berkvens et al., 2012). The cultural profile informed the research 
question of the dissertation, excavating what characteristics an effective professional development scenario should have, when aiming to strengthen the training facilitation skills of Ministry of Education staff in Cambodia in order to implement Education for All throughout the country. Although the preliminary research was small and did not pretend to be representative, it helped to gain a bit more solid ground underneath the interpretation of the cultural influence on education in Cambodia. It was found too important to not address separately, but in order to do that, some more solid ground needed to be sought.

The research presented in this article consists of four data sets utilized to shape the cultural profile of Cambodia following the five cultural dimensions of Hofstede $(1980,1986)$ :

1) The first data set, as a result of preliminary research carried out between 2006 and 2008, led to the first attempt to construct a Cambodian cultural profile;

2) The second data set, as a result of follow-up research, carried out in 2009 and 2010, and consolidated the emerged preliminary cultural profile;

3) The third data set is an analysis of unpublished work from Harmer (1995), unveiling Cambodian cultural changes after the Khmer rouge era, and was used to further strengthen the emerging cultural profile with previous research;

4) The fourth data set is a comparison of the closest cultural profile of Thailand in the work of Hostede (1980, 1986), with the cultural profile emerging from the research and was used to check the emerging cultural profile against the profile of culturally close country.

37 local Cambodian respondents (first data set) and 21 mainly international consultants working in Cambodia (second data set) were asked to participate through opportunity sampling. National respondents were selected from many socioeconomic strata, international respondents were all advising the ministry of education, in one way or another. In addition, four people regarded as 'experts' on Cambodia (both local and international) were asked to comment on the outcomes and conclusions.

The sample is by no means representative for the whole of Cambodian society, but by triangulating the findings of the four data sets presented here, a profile emerged that can at least help consultants to provide advice to the ministry that is culturally more relevant than is currently the case. In order to enhance reliability and validity of the findings presented here, triangulation of the findings coming forth from four different data sets presented in this paper has been carried out. Triangulation is a method often used in qualitative research to increase reliability and validity of findings in cases where single data set weaknesses can be compensated by the counterbalancing strengths of other data sets (Van den Akker, Gravemeijer, McKenney, \& Nieveen, 2006). A cross-analysis based on the four data sets was carried out to situate Cambodia on each of the five cultural dimensions of Hofstede. By comparing this proposed cultural profile with the cultural descriptions for education of Wursten and Jacobs (2016), a final check is provided to further solidify Cambodia's cultural profile. Wursten and Jacobs' work describes indicators for each cultural dimension based on the work of Hofstede (1980).

\subsection{The First Data Set: The Preliminary Research}

The original research was carried out between 2006 and 2009 in Cambodia (Berkvens, 2009), and consisted of a theorem-on-cards game. A total of 37 individual respondents played the theorem game. The respondents were selected following opportunity sampling: respondents were selected rather random: it could be colleagues in the ministry, family of friends, staff of a shop, or somebody in a cafe or shop. Based on the descriptions of the five dimensions of Hofstede, 16 theorems were developed and attributed to each dimension. Table 2 shows the theorems per dimension. Note that theorems 8 and 10 were found to contribute both to two dimensions and are therefore used twice.

Each respondent was explained the reason for the research, and was asked if they would be willing to participate. After having agreed, each participant was asked to work with a set of theorem cards. The theorem cards consisted of the statements (see table 2) in both Khmer and English. If a subject was found to be illiterate, the cards would be read out loud. Each theorem was put on a single card as a simple statement, to be understood easily, in both English and Khmer, and the cards were shuffled before being presented to a participant. The subject was then asked to agree, or disagree with the statement on the card, by putting the card on the appropriate pile (agree/disagree), or put it in the middle if in doubt. In the original version respondents were asked to put the cards on a continuum, but that was found to be too complex. Another issue was the translation of the theorems from English to Khmer and the reversed translation again to check for differences in meaning. Cambodian statements are usually structured with the addition 'men tei?' at the end, which is also a negative, and as such was already found to push answers in a certain direction. It took another round of reversed translations to arrive 
at acceptable Khmer translations.

Table 2. Theorems and score

\begin{tabular}{|c|c|c|c|c|c|}
\hline Item & Statement & Agree & $0 / 1$ & Disagree & $0 / 1$ \\
\hline 1 & $\begin{array}{l}\text { If I have to choose between my friend or my brother, I } \\
\text { choose my brother }\end{array}$ & Collectivist & 0 & Individualist & 1 \\
\hline 2 & $\begin{array}{l}\text { I believe people that people with power have more rights } \\
\text { than me }\end{array}$ & $\begin{array}{l}\text { Power distance } \\
\text { large }\end{array}$ & 0 & $\begin{array}{l}\text { Power distance } \\
\text { small } \\
\end{array}$ & 1 \\
\hline 3 & I sometimes question my religion & Uncertainty av. low & 1 & $\begin{array}{l}\text { Uncertainty av. } \\
\text { high }\end{array}$ & 0 \\
\hline 4 & Males and females are equal & Feminine & 1 & Masculine & 0 \\
\hline 5 & $\begin{array}{l}\text { I believe that a good Cambodian should follow strict rules } \\
\text { of behaviour }\end{array}$ & $\begin{array}{l}\text { Uncertainty av. } \\
\text { high }\end{array}$ & 0 & Uncertainty av. low & 1 \\
\hline 6 & Males and females have the same rights & Feminine & 1 & Masculine & 0 \\
\hline 7 & $\begin{array}{l}\text { If there is a car-accident between my brother and a } \\
\text { stranger, and I know it is my brother's fault... I will } \\
\text { protect the stranger }\end{array}$ & Individualist & 1 & Collectivist & 0 \\
\hline 8 & A good Cambodian respects tradition & $\begin{array}{l}\text { Short term } \\
\text { Uncertainty av. } \\
\text { high }\end{array}$ & $\begin{array}{l}0 \\
0\end{array}$ & $\begin{array}{l}\text { Long term } \\
\text { Uncertainty av. low }\end{array}$ & $\begin{array}{l}1 \\
1\end{array}$ \\
\hline 9 & I like unpredictable situations & Uncertainty av. low & 1 & $\begin{array}{l}\text { Uncertainty av. } \\
\text { high }\end{array}$ & 0 \\
\hline \multirow{2}{*}{10} & \multirow{2}{*}{ Cambodians are very ambitious } & Masculine & 0 & Feminine & 1 \\
\hline & & Long term & 1 & Short term & 0 \\
\hline 11 & I do trust another Cambodian I do not yet know & Collectivist & 0 & Individualist & 1 \\
\hline 12 & $\begin{array}{l}\text { If I can choose between a brand: Toyota Camry and a } \\
\text { Lexus, I choose the Camry }\end{array}$ & Feminine & 1 & Masculine & 0 \\
\hline 13 & I accept that there are power differences in Cambodia & $\begin{array}{l}\text { Power distance } \\
\text { large }\end{array}$ & 0 & $\begin{array}{l}\text { Power distance } \\
\text { small } \\
\end{array}$ & 1 \\
\hline 14 & I do not like situations that are unclear or unstructured & $\begin{array}{l}\text { Uncertainty av. } \\
\text { high }\end{array}$ & 0 & Uncertainty av. low & 1 \\
\hline 15 & In Cambodia we take care of our old people & Feminine & 1 & Masculine & 0 \\
\hline 16 & $\begin{array}{l}\text { Better to have a hard time to get it better in } 8 \text { years from } \\
\text { now, than a good time now }\end{array}$ & Long term & 1 & Short term & 0 \\
\hline
\end{tabular}

All characteristics of the respondents (age, school career, gender, locus of living) and their scores on each question were put in a spreadsheet. Every item could either have a score ' 0 ' or ' 1 ', after which the mean score per theorem and per accumulated dimension of Hofstede's model were calculated, delivering a score between ' 0 ' and ' 1 '. The score ' 0 ' would indicate one of the extremes of a dimension, the score ' 1 ' for the other extreme. The dimension score should be interpreted with caution, as the statistical base to approach the dimensions as scales is weak. Thus, for example, a score of 0.15 on one of the items within the collectivist versus individualist dimension would mean that that item suggests a fairly collectivist orientation. Percentages were also calculated.

The outcomes were analyzed following the five dimensions of Hofstede's model, leading to a preliminary cultural profile. In order to extend the trustworthiness of the developed profile, the conclusions were presented to four national and international 'Cambodia experts', each highly appreciated in the Cambodian education sector, and seen as 'nestors'. The nestors felt that the preliminary profile reflected their experience in Cambodia.

\subsection{The Second Data Set: The Follow-Up Research}

Towards the end of 2009 and at the beginning of 2010, the research was presented in Cambodia during two sessions: one for the colleagues in MoEYS, who participated in the bigger research on capacity development, and a second at the monthly education meeting, where ministry and stakeholders (including NGOs and aid bodies) inform each other on progress of their projects. During the latter meeting, an additional survey was conducted. The survey consisted of a mapping sheet. The dimensions were vertically ordered, and for each dimension the extremes were then separated with horizontal lines of ten centimeters. Each respondent was asked 
to position Cambodia along each dimension with a cross, between the two extremes. The location of the cross was then measured along each continuum, and calculated as an individual score, and a score for the sample for each of Hofstede's five dimensions. 21 respondents filled out the mapping sheet, mainly international stakeholders.

\subsection{The Third Data Set: Harmer's Research}

As was mentioned previously, only one more academic body of evidence on Cambodian culture had been discovered, by accident. This piece of work, written by Harmer in 1995 (Harmer, 1995), was never published, and the draft lacked the original data set. Attempts to retrieve the original data set failed so, unfortunately, further analysis remains impossible. But Harmer's work is interesting as it was conducted 322 Cambodians and tried to uncover the influence of the civil war on Cambodian culture. It was found to be rather easy to interpret Harmer's findings using the five dimensions of Hofstede's model, and it was possible to compare her findings with the findings of the current research.

\subsection{The Fourth Data Set: Thai Culture as a Comparison}

Cambodia is not included in Hofstede's work (1980, 1986), but other Asian nations are, with Thailand being the closest from both a geographic and cultural standpoint. The emerging Cambodian profile is compared with that of Thailand and other Asian countries.

\section{Results}

\subsection{The First Data Set}

The data of the original research, conducted under 37 local subjects, did not show any correlations between personal characteristics and the position along the five dimensions of culture. But the scores on the separate theorems do show that for three of the dimensions, the outcomes seem to be strongly skewed into one of the extremes, for the two other dimensions the theorem outcomes position Cambodian culture slightly off the center.

Table 3 shows the data on the collectivist versus individualist dimension, table 4 on the power distance dimension, table 5 on the uncertainty avoidance dimension, table 6 on the masculinity verses femininity dimension and table 7 on the short-term versus long-term dimension.

Table 3. Collectivist versus Individualist dimension

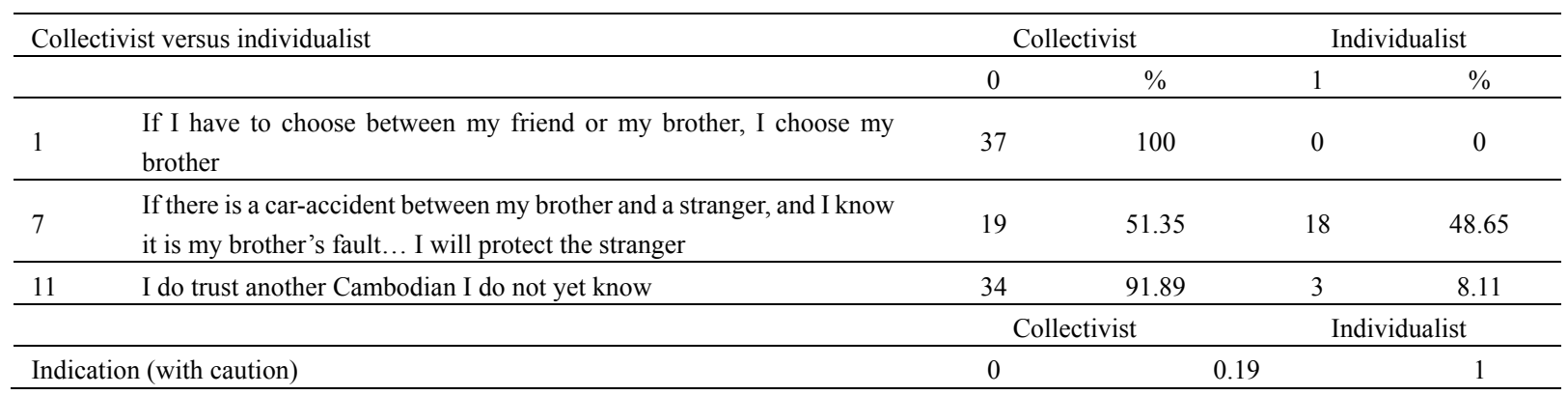

Table 4. Power distance dimension

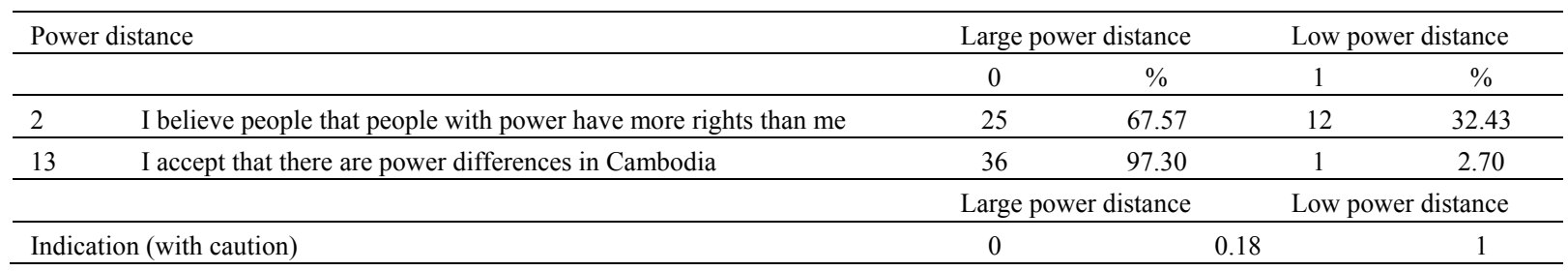


Table 5. Uncertainty avoidance dimension

\begin{tabular}{|c|c|c|c|c|c|}
\hline \multirow{2}{*}{\multicolumn{2}{|c|}{ Uncertainty avoidance }} & \multicolumn{2}{|c|}{ High uncertainty avoid. } & \multicolumn{2}{|c|}{ Low uncertainty avoid. } \\
\hline & & 0 & $\%$ & 1 & $\%$ \\
\hline 3 & I sometimes question my religion & 24 & 64.86 & 13 & 35.14 \\
\hline 5 & I believe that a good Cambodian should follow strict rules of behavior & 22 & 59.46 & 14 & 40.54 \\
\hline 8 & A good Cambodian respects tradition & 32 & 86.49 & 5 & 13.51 \\
\hline 9 & I like unpredictable situations & 26 & 70.27 & 11 & 29.73 \\
\hline \multirow[t]{2}{*}{14} & I do not like situations that are unclear or unstructured (S) & 26 & 70.27 & 11 & 29.73 \\
\hline & & \multicolumn{2}{|c|}{ High uncertainty avoid. } & \multicolumn{2}{|c|}{ Low uncertainty avoid. } \\
\hline Ind & n (with caution) & 0 & & & 1 \\
\hline
\end{tabular}

Table 6. Masculinity versus femininity dimension

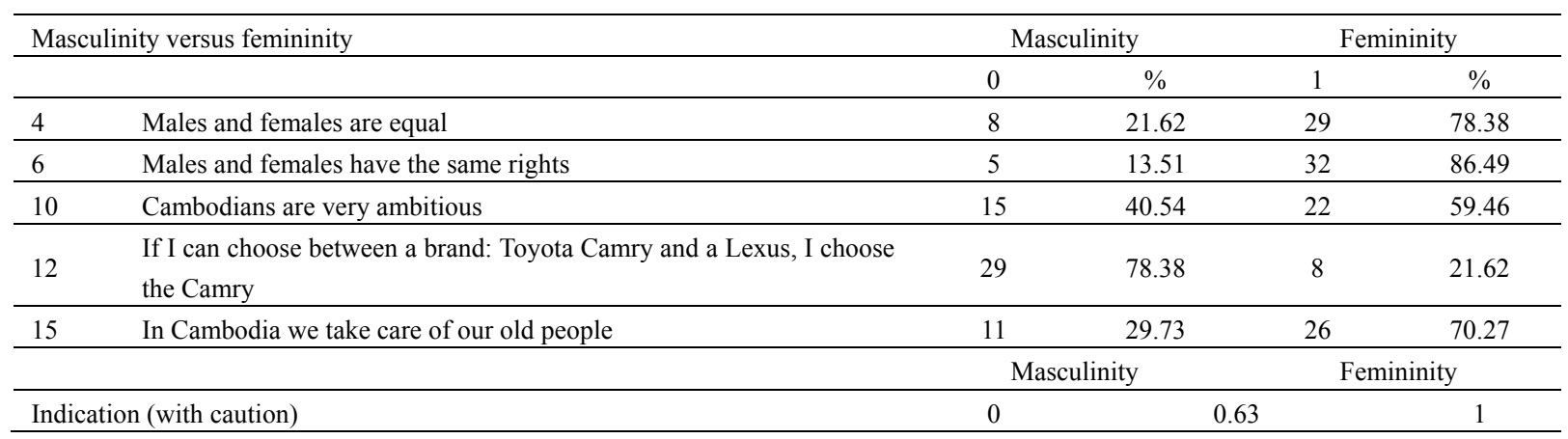

Table 7. Short-term versus long-term dimension

\begin{tabular}{|c|c|c|c|c|c|}
\hline \multirow{2}{*}{\multicolumn{2}{|c|}{ Short-term versus long-term }} & \multicolumn{2}{|c|}{ Short-term } & \multicolumn{2}{|c|}{ Long-term } \\
\hline & & 0 & $\%$ & 1 & $\%$ \\
\hline 8 & A good Cambodian respects tradition & 32 & 86.49 & 15 & 40.54 \\
\hline 10 & Cambodians are very ambitious & 15 & 40.54 & 32 & 86.49 \\
\hline \multirow[t]{2}{*}{16} & $\begin{array}{l}\text { Better to have a hard time to get it better in } 8 \text { years from now, than a } \\
\text { good time now }\end{array}$ & 10 & 27.03 & 27 & 72.97 \\
\hline & & \multicolumn{2}{|c|}{ Short-term } & \multicolumn{2}{|c|}{ Long-term } \\
\hline Ind & (with caution) & 0 & & & 1 \\
\hline
\end{tabular}

\subsection{The Second Data Set}

21 respondents filled out the mapping sheet, of which only one was a Cambodian national. His or her scores did not show any outliers. Some scores attract attention, as they are divergent but at the same time do not seem to be attributable to a shorter or longer stay in Cambodia. For example on the collectivist/individualist dimension, the scores of 5 and higher, are given by people that have been working in Cambodia between 7 and 204 months. So there is no explanation for these divergent scores based on this dataset. Stronger divergence was expected for the masculine/feminine dimension, as this dimension is more complicated to understand than the other four dimensions, but there was not more divergence than with the others.

The data set (Table 8) shows the score per respondent per dimension and the mean score of the sample per dimension. 
Table 8. Scores of consultants per dimension

\begin{tabular}{|c|c|c|c|c|c|c|c|}
\hline Subject & $\begin{array}{c}\text { Nationality } \\
\text { (0=Foreigner, } \\
\text { 1=Cambodian) }\end{array}$ & $\begin{array}{c}\mathrm{N} \text { of } \\
\text { months in } \\
\text { Cambodia }\end{array}$ & $\begin{array}{c}\text { Dimension } 1 \\
\text { Collectivist/individualist }\end{array}$ & $\begin{array}{c}\text { Dimension } \\
2 \\
\text { Power } \\
\text { distance }\end{array}$ & $\begin{array}{c}\text { Dimension } 3 \\
\text { Uncertainty } \\
\text { avoidance }\end{array}$ & $\begin{array}{c}\text { Dimension } 4 \\
\text { Masculinity/femininity }\end{array}$ & $\begin{array}{c}\text { Dimension } 5 \\
\text { Short-term/long-term }\end{array}$ \\
\hline 1 & 0 & 42 & 5 & 1.5 & 2 & 3 & 0.5 \\
\hline 2 & 0 & 90 & 2.5 & 2 & 2.5 & 3 & 2.5 \\
\hline 3 & 0 & 84 & 4 & 2.5 & 2.5 & 1.5 & 2 \\
\hline 4 & 0 & 5 & 2.5 & 2.5 & 6 & 1.5 & 3 \\
\hline 5 & 0 & 132 & 2.5 & 2.5 & 1 & 2 & 2.5 \\
\hline 6 & 0 & 183 & 3 & 2 & 2 & 5.5 & 8 \\
\hline 7 & 0 & 176 & 1.5 & 1.5 & 2 & 1 & 1.5 \\
\hline 8 & 0 & 38 & 7 & 2 & 2 & 1.5 & 1.5 \\
\hline 9 & 0 & 175 & 2 & 1.5 & 2 & 1.5 & 1.5 \\
\hline 10 & 0 & 36 & 4.5 & 1.5 & 1.5 & 4.5 & 2 \\
\hline 11 & 0 & 204 & 7 & 3 & 3 & 3 & 3 \\
\hline 12 & 0 & 24 & 3 & 1 & 1 & 6.5 & 1 \\
\hline 13 & 0 & 83 & 2 & 2 & 2 & 2 & 2 \\
\hline 14 & 0 & 4 & 1.5 & 1.5 & 1 & 1.5 & 4.5 \\
\hline 15 & 0 & 101 & 2 & 1.5 & 2 & 1.5 & 3 \\
\hline 16 & 0 & 43 & 1 & 1 & 1 & 2 & 1.5 \\
\hline 17 & 0 & 42 & 2.5 & 2.5 & 2.5 & 2 & 2.5 \\
\hline 18 & 0 & 180 & 1.5 & 1 & 1 & 2.5 & 1 \\
\hline 19 & 0 & 7 & 7 & 2 & 2.5 & 3.5 & 2 \\
\hline 20 & 0 & 120 & 4.5 & 2 & 2 & 3.5 & 2.5 \\
\hline 21 & 1 & 204 & 1.5 & 2 & 1 & 1.5 & 1.5 \\
\hline Average & & 93.95 & 3.23 & 1.85 & 2.02 & 2.59 & 2.35 \\
\hline Scaled & & & 0.32 & 0.19 & 0.20 & 0.26 & 0.24 \\
\hline
\end{tabular}

\subsection{The Third Data Set}

As was mentioned previously, only one more academic body of evidence on Cambodian culture had been discovered by accident. This piece of work written by Harmer (1995) was never published, But is of interest as it was conducted 322 Cambodians and tried to uncover the influence of the civil war on Cambodian culture. It was rather easy to interpret Harmer's findings using the five dimensions of Hofstede's model, and it was possible to compare her findings with the findings of the current research.

Harmer (1995) describes the extended family (nuclear family and other relatives living nearby) to be of great importance before the Khmer Rouge era. During their regime, the Khmer Rouge forced Cambodians into 'enforced collectivism', in which traditional social, economic and cultural relations were disrupted (p. 3). After the Khmer Rouge period, extended family members became more important, as so many families were depleted of their members. The findings of the 1994 focus groups conclude that Cambodian society after the Pol Pot regime was less collectivist than before the Khmer Rouge era. That conclusion was based on the fact that people experienced greater poverty, and less solidarity with others than with immediate family. People were thought to be less willing to enroll in activities benefiting the wider community. Families were more splintered in 1994 than before the Khmer Rouge time in order to pursue income. Male/female relationships were less stable and moral standards seemed to be in decline.

The findings indicate that politicians in 1994 were mostly interested in power and that they were greedier than before. Participants agreed on the perception that there was more corruption and exploitation; leading to run-down civil services and economy (the latter is disputable now, with a yearly economic growth rate of a steady 9\% over the last ten years (Asian Development Bank [ADB], 2008)). It was felt that before 1970 politicians were less corrupt and that they strove for good Governance by providing services like health care and education. Harmer (1995) continues to postulate that 'traditionally, Cambodian society has emphasized preservation of the status quo, a tolerance of suffering and injustice and conformity to higher authority' (pp. 10-11), and that this is connected with Buddhist notions of acceptance of suffering and having been oppressed 
for so long. She further implies that Cambodians may accept living with the burden of suppressed emotion on cultural and historical grounds.

Harmer's data show that most Cambodians uncritically accept their Buddhist religious dogmas. Coping mechanisms from previous wartime and trauma such as mistrust, passivity and preservation of self-interest as described by Harmer are difficult to classify but fit best under uncertainty avoidance, as they contribute to extension of the status quo. The focus-group discussions concluded that there was more lawlessness, violence and anarchy in 1994 than before. People were more afraid for their personal security than before the Khmer rouge, indicating stronger uncertainty avoidance. On the other hand, however, traditional practices were perceived to be less celebrated and people were thought to be less superstitious and more open toward Western culture than before. These are indications of reduced uncertainty avoidance.

The respondents agreed on the perception that before the Khmer Rouge time Cambodians were kind and gentle. People were proud of their country and nation. In 1994 Cambodians were still thought to be kind and gentle, but were also selfish, greedy, jealous and violent. Participants also agreed that many people in 1994 could not afford to send their children to school. If a choice had to be made between a girl and a boy it would usually be the boy that was sent to school, although there was recognition that education is also appropriate for girls, which could be an indication of long-term orientation. In general, people were thought to be less hard-working than before Pol Pot, although there was more interest in modern technology than before. Another conclusion of the focus groups was that Cambodians showed symptoms of aid-reliance, dependency, passivity and hopelessness. These are signs of a more short-term orientation.

\subsection{The Fourth Data Set}

Thailand, as most Asian countries, is a highly collectivist country. Thai are not confrontational and in there communication a "Yes" may not mean an acceptance or agreement. An offence leads to loss of face and Thai are very sensitive not to feel shamed in front of their group. Personal relationship is key to conducting business and it takes time to build such relations thus patience is necessary as well as not openly discuss business on first occasions. The country scores relatively high on power distance, but slightly lower than most other Asian countries in the research. Inequalities are accepted, and hierarchy and protocol are respected. Each rank has its privileges and employees show loyalty, respect and deference for their superiors in return for protection and guidance. The attitude towards managers is formal, and communication is hierarchical and controlled. Thai have a preference for avoiding uncertainty. In order to reduce uncertainty, strict rules, laws, policies, and regulations are adopted and implemented. People try to avoid the unexpected. Society does not readily accept change and tries to avoid risk. Thailand society is considered feminine. Thailand has the lowest Masculinity ranking among the average Asian countries and the World. Thai are less assertive and competitive. This situation also reinforces more traditional male and female roles within the population. Thai culture is a long-term oriented culture though not as much as for most Asian countries. They respect tradition and inequality between people. Amongst the values that are praised, working hard and having a sense of moderation are dominant. The investment in personal relationships and network is paramount. Protecting one's face is key. Thai favor long-term oriented perspectives and thus Thailand deadlines and timescales are fluid.

\subsection{Triangulation of the Findings}

\subsubsection{The Collectivist/Individualist Dimension}

The data sets indicate a more collectivist orientation. Item 11 of the original research would, at first sight, be a negative indicator for collectivist orientation, but could, after further analysis, be seen as an indicator for collectivism in the Cambodian context: Harmers' (1995) research showed that lack of trust has increased as a result of the Khmer rouge and civil war period, leading to much smaller in-groups of the collectivist structure in Cambodia. As such, it is not surprising that the respondents overwhelmingly said that they would not trust others they do not know yet $(92 \%)$. How strong the in-group orientation is, can be deducted from the first item ('If I have to choose between my friend and my brother, I choose my brother'). All respondents favored their spouse over their friend. The response to item seven partly confirms a strong preference towards the in-group. Asking the respondents what they would do if their brother caused a car accident, either protect their spouse or the unknown victim even when knowing their spouse was wrong, about half (49\%) of the respondents said that they would try to protect their spouse, even if they knew s/he was accountable for the accident.

Other Asian countries like Thailand, Hong Kong, Korea and Taiwan also show a more collectivist orientation (Hofstede, 1980, 1986). According to Wursten and Jacobs (2016), collectivist implications for education are that students only speak up when called on by the teachers, individuals only speak up in small groups, formal harmony in learning situations at all times over a learning environment characterized by confrontation and 
challenge, teachers nor students should ever be made to lose face, and teachers are expected to give preferential treatment to some. All of these implications are readily visible in Cambodian classrooms.

\subsubsection{The Power Distance Dimension}

The data suggest a large power distance. The consultants score .19 on this dimension, the two items of the Cambodian respondents on this dimension rate .32 and .03 . The difference between these two items could be explained by the subtle difference between the two statements. Statement two asked the respondents whether they believe that people with power have more rights than themselves, statement 13 asked if they accept those power differences. Although more respondents believed that (32\%) people with more power do not have more rights, only one respondent said not to accept these power distances.

Harmer's (1995) work also implies a large power distance, and that this power distance was larger than before the civil war. The respondents believed that politicians before made more work on good governance. Others reject this positive representation (Ayres, 2000; Wijers, 2013). They argue that Cambodia has always had a 'patron-client system' emphasizing reciprocal relationships. Harmer suggests that Cambodians may accept living with the burden of suppressed emotion on cultural and historical grounds.

Thailand has an intermediate power distance (Hofstede, 1980, 1986). One of the 'Cambodia experts', a local government official, explained that the Cambodia's large power distance is a consequence of the civil war and returned peace afterwards: 'many of us feel that peace is more important, so we accept'. Harmer (1995) described a similar explanation. Wursten and Jacobs' (2016) descriptions resemble Cambodian education: teaching is teacher centered, teachers outline the paths and initiate communication, students hardly contradict nor criticize teachers and teacher effectiveness is seen a function of their excellence.

\subsubsection{The Dimension of Uncertainty Avoidance}

Uncertainty avoidance rates as strong, in all data sets. The consultants seem to be a bit more critical than the Cambodian respondents of the original research, rating Cambodia .20. The scores on the statements of the original research show that the respondents strongly respect tradition (86\%), and that $70 \%$ of the respondents felt uncomfortable with unknown, unstructured and unpredictable situations. Harmer (1995) confirms stronger uncertainty avoidance in Cambodia than before the Khmer Rouge era.

Thailand also shows strong uncertainty avoidance (Hofstede, 1980, 1986), but not as strong as Cambodia. Again, the recent pasts of civil war, but also the historical perspective of patronage, are probable explanations for this position on the uncertainty avoidance dimension. Wursten and Jacobs (2016) describe high uncertainty avoidance implications on teaching as a preference for structured learning situations, teachers expected to have all the answers and use academic language, students are rewarded for accuracy instead of for innovative approaches, and intellectual disagreement is seen as personal disloyalty instead of stimulating.

\subsubsection{The Masculine/Feminine Dimension}

The masculine/feminine dimension shows a more confusing picture. The Cambodians in the original research strongly feel that their society takes care of the elderly (link with the collectivist dimension), and men and women are perceived as equal. The Cambodian respondents rated 'being ambitious' more towards the feminine, less ambitious, side (.60), but this could be a consequence of the violent past, in which being ambitious was not favored (by the Khmer Rouge) and was unfruitful (as a result of the demolition of following destructive waves during the civil war). More masculine traits, however, are also favored, as is shown by the scores on item 12. A Lexus car is highly favored over a simpler Toyota Camry (a car that is often used as a taxi) (86\% vs. $14 \%$ ). Harmer (1995) confirms a move in the direction of more masculine behavior, at least for the ones in power. The description of how Cambodians were before the Khmer Rouge regime, however, is feminine to the extreme, arousing some caution of response bias.

Compared to Thailand, Cambodia would take a similar position as Thailand. Thailand is also on the feminine side of the dimension, although some more masculine behavior can be identified (Hofstede, 1980, 1986). The consultants (second data set), however, rate Cambodian society as more masculine. This could be explained through the fact that in politics it is mostly men who hold higher positions, in a system that is based on large power distance, patronage and nepotism. Wursten and Jacobs' (2016) work on the implications for this dimension show a similar ambivalence: many teachers use the best students as norm, students' failure is a blow to student self-image and students choose school subjects for career reasons, not out of interest (all masculine implications). But students also try to behave modestly and social adaptation is seen as important as academic performance (feminine implications). 


\subsubsection{The Short-Term/Long-Term Orientation}

Most respondents describe Cambodian orientation as being more short-term. Although the Cambodians in the first data set seem to be a bit less strong on how short-term that orientation is, it could also be argued that the item that draws the orientation a bit more towards the middle ('better to have a hard time to get it better in eight years from now, than a good time now'), is debatable: The statement is probably more easily favored than carried. One would need to have a steady and profitable job to actually benefit from working hard in order to get a better future. Many Cambodians lack that kind of opportunity. The stronger score for short-term orientation given by the consultants in the second data set is also not very surprising: many consultants are hired to oversee and manage projects, of which planning is usually quite an extensive part for which they have to take responsibility. Maybe the terminology long- and short-term planning for international development work is actually not really adequate, as many projects have limited running times and solid deadlines for achieving rather strict deliverables, thus a more adequate term would be 'strict planning' instead of long-term planning. As a result, the need for strict and full-project planning is high, and international organizations find it generally hard to find capable staff to do so. Another consequence of the relatively short project time lines is that the strict planning of projects might not always compare with local development and organizational agendas, contributing to the international consultants' opinion that Cambodia's orientation is more short-term.

Harmer (1995) also reflects ambiguity on this dimension. The hopelessness and passivity that she mentions is still widely visible, but at the same time many Cambodians constantly make enormous efforts to meet their daily needs and work and study hard to alleviate poverty.

Hofstede $(1980,1906)$ describes Thailand as a long-term oriented society, but not as strong as other nations in Asia. Cambodia would even further be towards short-term orientation, most probably as a result of a combination of the patronage system and the recent history. The ambivalence between Cambodian education and Wursten and Jacobs (2016) implications for this dimension is striking. Half of the implications reflecting Cambodian educational practice point towards short-term orientation (Focus is on asking 'why', students expect to find the one and only solution), while the other half points towards long-term orientation (strong emphasis on education as obligation, and perseverance is seen as an important virtue).

\section{Conclusion}

The data confirm the following emerging Cambodian cultural profile: i) a more collectivist nature, with some tendencies towards individualistic behavior; ii) a quite large power distance, meaning that people tend to accept the power differences although they may not appreciate it; and iii) a relatively high uncertainty avoidance, meaning that Cambodians tend to avoid unstructured, unpredictable and unclear situations. On the dimensions of masculinity and femininity, the data are less convincing. The Cambodian sample shows that Cambodians classify their culture as slightly more feminine minded, whereas the data set reflecting the ideas of the (mainly foreign) consultants shows that Cambodian culture is perceived as quite strongly masculine. The second dimension that is slightly aberrant is that of short-term versus long-term orientation: Both datasets confirm a short-term orientation, although the Cambodian subjects seem to be more long-term oriented.

The changing character of Cambodia is clearly visible, due to economic growth and increased influence from outside. At the same time, many aspects of life still remain very traditional. Cambodian culture is not a clear-cut given. The recent past contributes to that. Culture is seldom defined through one main channel, as many bodies could be identified as carriers of culture, i.e. writers, theatre makers, teachers, religious leaders, musicians, and families and communities themselves. During the Khmer Rouge regime many of these carriers were eliminated, and the long period of civil war and poverty that followed did not allow for reestablishing of these carriers. The main cultural carriers that were are of religious background. This fact is likely to contribute to the unbalanced cultural profile that is identified through this research.

The research presented here is of informative nature, with small samples and, sometimes, disputable strength. It is also one of the few more serious attempts to describe Cambodian culture in a more substantiated way than the cultural guidebooks and anecdotal writings do. The research was carried out in the light of educational development, but the cultural profile that emerged is not solely based on the opinion of people working in Cambodia's educational sector and, therefore, might be of practical use in other sectors. As one of the Cambodian experts reflecting on this cultural profile said: 'Cambodia is more than the Khmer Rouge'. A better understanding of contemporary culture could be beneficial to anyone working in Cambodia.

The triangulation approach taken allows for a cultural profile for Cambodia that, when used carefully, can guide development work in education and probably other sectors. The following examples come forth from professional observations during my three years in the Cambodian Ministry of Education. The first example 
describes how learning in workshops and trainings could be improved: Participants of workshops and training sessions are often lectured, without any practical sessions. A combination of theory and practice could improve learning outcomes and implementation, understanding of power distance and uncertainty avoidance would help to design approaches that motivate learners to enroll in such learning endeavors, instead of trying to avoid engagement. A second example is the fact that facilitators of workshops are often perceived as 'higher in hierarchy'. Participants show reluctance to ask questions or provide comments. Many -especially foreign facilitators- misinterpret the continuous nodding of their listeners as having their participants engaged and following, while it is more often a sign of 'continue, maybe I will understand what you are talking about'. A final example of how power distance and uncertainty avoidance can lead to immense implementation problems of educational reforms, is that of an American consultant who was leading a pilot for ICT education preceding national rollout: The pilot schools were supposed to be representative for the situation in schools in the country, but due to the rainy season, only schools on tarmac and close to the capital were reachable for the Ministry staff. Instead of sharing this with the consultant, Ministry staff chose the close-by schools and renamed the schools at the end of the pilot. All these schools had good infrastructure including access to electricity, security, etc. Most schools further away from the capital did not, leading to tremendous complications by the time of nationwide roll out. It is highly likely that such examples of cultural misunderstanding can lead to similar problems in other sectors as well.

Combining the outcomes of this research with the claim Wursten and Jacobs (2016) make-education should be improved with respect for the local cultural context, one could conclude that projects like Child Friendly Schools and many other similar initiatives do work from a different cultural paradigm than the profile presented in this research. This has consequences, both for project outcomes, as for the communities these projects are implemented in. The implications thereof are yet to be well understood, but the complications sometimes do surface. One such example is of the young school girl who learned to ask interrogative questions at school, something that was not appreciated at home in the local community, leading to violence in the community. Another example is that of a teacher who lost authority in the school and the community, while trying to teach her class to be more exploratory while not knowing the answers to the questions that arose. How successful the introduction of approaches like CFS can be when the approaches are not culturally adapted, is at least doubtful.

\section{References}

ADB. (2008). ADB and Cambodia factsheet 2008. Retrieved April 18, 2010, from www.adb.org/Documents/Fact_Sheets/CAM.pdf

Ayres, D. M. (2000). Anatomy of a crisis. Education, development, and the state in Cambodia, 1953-1998. Hawaii: University of Hawaii Press.

Berkvens, J., Kalyanpur, M., Kuiper, W., \&, Van den Akker, J. (2012). Improving Adult Learning and Professional Development in a post-conflict area: the case of Cambodia. International Journal of Educational Development, 32(2), 241-251. https://doi.org/10.1016/j.ijedudev.2011.03.008

Berkvens, J. B. Y. (2009). Developing professional learning in Cambodia (PhD thesis, Enschede, Twente University).

Chandler, D. P. (2007). A history of Cambodia. New York: The Persues Books Group.

Fröberg Idling, P. (2009). De glimlach van Pol Pot. Amsterdam: Nieuw Amsterdam uitgevers.

Harmer, A. (1995). Rebuilding war-torn societies: psycho-social vulnerability and coping mechanisms in Cambodia. A social research feasibility study.

Hill, D. (2005). Do's and don't's in Cambodia. Bangkok: Book promotion and service Co., Ltd.

Hofstede, G. (1980). Culture's consequences: International differences in work-related values. Beverly Hills: Sage.

Hofstede, G. (1986). Cultural differences in teaching and learning. International Journal of Intercultural Relations, 10, 301-320. https://doi.org/10.1016/0147-1767(86)90015-5

Hofstede, G., \& McCrea, R. R. (2004). Personality and culture revisited: Linking traits and dimensions of culture. Cross-Cultural Research, 38, 52-88. https://doi.org/10.1177/1069397103259443

Peterse, L., \& Petri, J. (2004). Cambodja. Haarlem: Gottmer Uitgevers Groep.

Shaeffer, S., \& Heng, K. (2016). Child-friendly school policy implementation in Cambodia. April-October 2016. Final report. Phnom Penh: MoEYS \& Unicef Cambodia. 
Taylor, C., Wheeler, T., \& Robinson, D. (1996). Cambodia. Travel survival kit. Hawthorn: Lonely Planet.

The Economist Intelligent Unit. (2012). The learning curve, 2012. Lessons in country performance in education. 2012 report. London: Pearson.

UN Sustainable Development Knowledge Platform. (2015). Sustainable development goals. Retrieved April 12, 2017, from https://sustainabledevelopment.un.org/?menu=1300

Van den Akker, J., Gravemeijer, K., McKenney, S., \& Nieveen, N. (2006). Educational design research. Abingdon, Axon: Routledge.

Verkoren, W. (2005). Bringing it all together: A case study of Cambodia. In G. Junne, \& W. Verkoren (Eds.), Postconflict development; meeting new challenges (pp. 289-306).

VSO. (2006). Cultural do's and don't's. Handout for volunteer. Phnom Penh: VSO.

Wijers, G. (2013). Navigating a river by its bends (Doctoral dissertation, Amsterdam: VU University Press).

Wursten, H., \& Jacobs, C. (2016). The impact of culture on education. Can we introduce best practices in education across countries? Retrieved February 24, 2017, from https://www.academia.edu/12349034/The_impact_of_culture_on_education

\section{Copyrights}

Copyright for this article is retained by the author(s), with first publication rights granted to the journal.

This is an open-access article distributed under the terms and conditions of the Creative Commons Attribution license (http://creativecommons.org/licenses/by/4.0/). 